\title{
Implementing ERP Systems in Higher Education Institutes Critical Success Factors Revisited
}

\author{
Christian Leyh; Anne Gebhardt; Philipp Berton \\ Technische Universität Dresden; Chair of Information Systems, esp. IS in Manufacturing and Commerce \\ Helmholtzstr. 10, 01069 Dresden, Germany \\ Email: Christian.Leyh $@$,tu-dresden.de
}

\begin{abstract}
The aim of our study is to investigate ERP project critical success factors (CSFs) with a focus on higher education institutes (HEIs). We conducted a systematic literature review to identify specific CSFs affecting HEIs' project outcome. Building on these results, we led several interviews within selected German HEIs. Overall, there is little literature dealing with the HEIs' CSFs, but nearly all factors found in the literature were also mentioned by the interviewees. However for HEIs, factors like ERP system tests or ERP system configuration are even more important than Top management support or Project management that are the most important CSFs in general studies. Our study shows that in spite of the maturity of the field, revisiting CSF research for specific types of organizations/ institutions is still worthwhile.
\end{abstract}

\section{MOTIVATION AND BACKGROUND}

$\mathrm{N}$ OWADAYS, companies need to be able to efficiently and effectively react to rising globalization as well as changing markets and economic conditions. However, public bureaucracy and especially higher education institutes (HEIs) such as universities and universities of applied sciences are facing similar challenges as private enterprises. They not only have to respond to far reaching changes in government and society but also have to compete nationally and internationally. Challenges include declining financial support from state-level governments, unpredictable fluctuation of student numbers, globalization, and global competition among universities as well as increasing competition on the national level for students, scientists, and third-party funds. Therefore, as a result of these changing conditions, universities need the highest possible efficiency and effectiveness in their administrative processes as stated by several researchers (e.g., [1]-[6]).

Given these numerous and varied challenges, the task is to find organizationally and technologically suitable solutions to these requirements. In order to create effective and efficient management and administrative processes and to bundle resources and databases, universities (mostly large HEIs) have started to implement integrated application systems (e.g. ERP systems) beginning in the mid-1990s, and especially during the 2000s. Attention is given to similar concepts that have been effective in integrated information processing in the corporate world [3], [7]. Several benefits result from the implementation of ERP systems for universities [4], [8]:

- improved information supply and flow for planning and controlling processes of the university;

- improved service for faculties, students, and staff;

- lower business risks;

- reduced expenditures through increased process efficiency.

The implementation of integrated application systems such as ERP systems is a complex and time-consuming project during which organizations face both great opportunities and enormous risks. Furthermore, these implementations often require significant organizational changes. Implementation at universities represents a doubly difficult task as these systems influence both the academic and administrative fields. Here, approaches that have proven successful during the last decades for the implementation of application systems in private companies cannot be transferred equally to projects in HEIs [2]. This must be taken into account when implementing ERP systems at HEIs. In addition, vendors have less experience with the implementation of application systems in universities than in enterprises. To take advantage of the potential opportunities rather than get caught by the risks of these implementation projects, it is essential to focus on those factors that support a successful implementation of an information system. By being aware of these factors, an organization (private enterprise or HEI) can positively influence the success of the implementation project and effectively minimize the project's risks [9]. Recalling these so-called critical success factors (CSFs) is of high importance whenever a new system is to be adopted and implemented or a running system needs to be upgraded or replaced.

In recent years, several studies have been published in which specific information system implementation projects at selected universities are considered and analyzed (e.g., [4], [6], [7], [8]). However, none of these studies provide insight into the CSFs of those implementation projects at universities. The existing ERP system success factor research (e.g., [10]-[14]) has focused mostly on the selection and implementation of ERP systems in private enterprises. Less or even no attention has been paid to the implementation projects in HEIs.

In our opinion CSFs are useful and a fruitful path to increase understanding of the complex organization-IT 
relationship. Therefore, it is worthwhile to continue research in the area. For example, it is valuable to revisit old frameworks to check their validity and also their adoption by practice. Moreover, the use of ERP systems in "new types" of organizations, such as HEIs, motivates our research. Identifying and recalling, as well as considering the CSFs for ERP projects at HEIs can still be seen as an important issue.

Therefore, the central objective of our research project was and still is the detailed investigation of ERP implementation project CSFs for HEIs. To achieve this goal, we set up a study with a specific focus on the implementation of ERP systems in HEIs' administrations. Overall, our study was driven by the following research questions:

- Q1: What are the critical success factors of ERP system implementation projects in HEIs?

- Q2: What similarities and differences exist between critical success factors for ERP implementation projects in HEIs and private enterprises?

To answer those questions, as a first step in our study, we conducted a systematic literature review in order to detect already identified CSFs for HEI ERP implementations. On the basis of the CSFs identified, we conducted multiple interviews within German HEIs to obtain insights into the CSFs for their ERP system implementation projects. We focused on German HEIs in this step as an initial starting point for our investigation due to our cultural background.

Selected results of this first step will be presented within this paper. Therefore, the paper is structured as follows. The following section deals with the results of our literature review. Next, our data collection methodology is described and the results of the interview study are presented. Finally, the paper concludes with a summary of the results and discusses the limitations of our study.

\section{LITERATURE REVIEW - CRITICAL SUCCESS FACTORS FOR HEI ERP IMPLEMENTATIONS}

\section{A. Procedure of the Literature Review}

A critical success factor for an ERP project is defined according to [13] as a reference to any condition or element that is seen as necessary in order for the ERP implementation to be successful. However, not every CSF has the same impact on the success of every project. Therefore, we are also referring to the definition of [11] who see CSFs as "a number of factors that may affect the ERP implementtation process and the probability of conversion success."

With regard to our research questions, we conducted a literature review by systematically reviewing articles in five different databases, as well as papers drawn from several international conference proceedings. The literature review was performed in several steps, similar to the approaches suggested by [15], [16]. More specifically, we had already conducted several literature reviews with a focus on the CSFs of ERP implementations at private enterprises (e.g., [14], [17]) and thereby, we have adapted our review approach according to the experience we gained during those reviews.
Step 1: The first step was to define the sources for the literature review. Therefore, five databases (Academic Search Complete, Business Source Complete, Science Direct, SpringerLink, and WISO) and conference proceedings (AMCIS, ECIS, HICSS, ICIS, and Wirtschaftsinformatik conference) were identified.

Step 2: In this step, we had to define the search terms for the database-driven review. Keywords selected for this search were mostly derived and adapted from the keywords supplied and used during our previous CSF reviews (e.g., [14], [17]). Example search terms that we used are listed in Table I. Since the WISO database also includes German papers, we additionally used the German translation of the search terms. For the conference papers, only inappropriate search fields were provided. Hence, we decided to manually review the abstracts and titles of the papers in this step.

TABLE I.

SEARCH FIELDS AND SEARCH TERMS

\begin{tabular}{|c|c|}
\hline Database + search fields & $\begin{array}{c}\text { Examples of search terms / } \\
\text { keywords }\end{array}$ \\
\hline $\begin{array}{l}\text { Academics Search Complete: } \\
\text { "TI Title" or "AB Abstract or } \\
\text { Author Supplied Abstract" }\end{array}$ & $\begin{array}{l}\text { ERP + university + success* } \\
\text { ERP + university + failure } \\
\text { ERP + university + crit* }\end{array}$ \\
\hline $\begin{array}{l}\text { Business Source Complete: } \\
\text { "TI Title" or "AB Abstract or } \\
\text { Author Supplied Abstract" }\end{array}$ & $\begin{array}{l}\mathrm{ERP}+\text { higher education }+\mathrm{CSF} \\
\mathrm{ERP}+\text { higher education }+\mathrm{CFF} \\
\mathrm{ERP}+\text { higher education }+ \text { fact* }\end{array}$ \\
\hline $\begin{array}{l}\text { Science Direct: } \\
\text { "Abstract, Title, Keywords" }\end{array}$ & $\begin{array}{l}\text { "Enterprise system*" + university } \\
+ \text { success } *\end{array}$ \\
\hline $\begin{array}{l}\text { SpringerLink: } \\
\text { "Title" or "Abstract" }\end{array}$ & $\begin{array}{l}\text { "Enterprise system*" + university } \\
+ \text { failure }\end{array}$ \\
\hline $\begin{array}{l}\text { WISO: } \\
\text { "General Search Field" }\end{array}$ & $\begin{array}{l}\text { "Enterprise system*" + university } \\
+ \text { crit* }\end{array}$ \\
\hline
\end{tabular}

Step 3: During step 3, we performed the initial search according to step 1 and step 2 . The initial search provided 6,963 papers from the databases. From the conference search, 34 papers remained. Altogether, 6,997 papers were identified during this initial search step.

Step 4: Step 4 included the identification of duplicates and irrelevant papers. During the initial search, we did not apply any restrictions. The search was not limited to the research field of IS; therefore, papers from other research fields were included in the results, too. Thus, these papers had to be excluded. This was done by reviewing the abstracts of the papers and, if necessary, by examining the papers' content. The elimination of duplicates was done by using the literature management software Mendeley (https://www.mendeley.com/) where duplicates are automatically identified during the literature import process. Of the papers, 185 stemming from the database search and all 34 conference papers remained. Altogether, this step yielded 219 papers potentially relevant to the field of CSFs for ERP system implementations at HEIs.

Step 5: The fifth step consisted of a detailed analysis of the remaining 219 papers and the identification of the CSFs. Therefore, the content of all papers was reviewed in depth. Emphasis was placed not only on the wording of the CSFs 
but on their meaning. Following this step, only eight relevant papers that suggested, discussed or mentioned CSFs in the context of HEI ERP implementations remained.

Step 6: Because of the small number of relevant papers, we applied (contrary to our previous reviews) a sixth step during which the references of the eight relevant papers were searched to identify suitable papers. With this method, we could identify seven additional papers addressing the field of ERP projects at HEIs. Therefore, we had a list of 15 relevant papers for further investigation. The identification of the additional seven papers also shows that papers focusing this topic are not all published in the "main" publication channels. Those papers often stemmed from smaller conferences or journals not indexed in the used databases.

\section{B. Results of the Literature Review}

The identified 15 papers were again reviewed in depth in order to determine the various concepts associated with CSFs. For each paper, the CSFs were captured, along with the publication year, the type of data collection used, and the HEIs (i.e., the number and size) from which the CSFs were derived. Overall, 30 different factors were identified. In most previous literature reviews of other researchers with a focus on private enterprises, the CSFs were grouped more coarsely so that a lower number of CSFs was used (e.g., [11], [13]). The grouping was neither done within our review nor within our own previous reviews ([14], [17]). With 30 factors, we used a larger number than earlier researchers had because we expected the resulting distribution to be more insightful.

While identifying the CSFs within the papers, no special weighting of the factors was used. This means that each success factor that has been addressed within a paper will considered with " 1 " in our result list. Afterwards, we counted these numbers. Table II lists the identified success factors according to their frequency.

\section{TABLE II}

CSF'S IN RANK ORDER BASED ON FREQUENCY OF APPEARANCE IN ANALYZED LITERATURE

\begin{tabular}{|l|c|}
\hline \multicolumn{1}{|c|}{ Factor } & $\begin{array}{c}\text { No. of } \\
\text { instances }\end{array}$ \\
\hline Top management support and involvement & 8 \\
\hline Communication & 8 \\
\hline User training & 8 \\
\hline Balanced project team (cross-functional) & 6 \\
\hline Involvement of end-users and stakeholders & 6 \\
\hline Change management & 6 \\
\hline Project management & 6 \\
\hline Organizational Culture & 5 \\
\hline Interdepartmental cooperation & 5 \\
\hline ERP system acceptance / resistance & 5 \\
\hline Organizational fit of the ERP system & 5 \\
\hline External consultants & 5 \\
\hline Clear goals and objectives (e.g., vision, decision strategies) & 5 \\
\hline Vendor relationship and support & 4 \\
\hline Project leadership / empowered decision makers & 3 \\
\hline Skills, knowledge, and expertise & 3 \\
\hline IT structure and legacy systems & 3 \\
\hline Business process reengineering & 3 \\
\hline Environment (e.g. language, culture) & 3 \\
\hline Data accuracy (analysis and conversion) & 3 \\
\hline
\end{tabular}

\begin{tabular}{|l|c|}
\hline Organizational structure & 2 \\
\hline Available resources (e.g. employees, budget) & 2 \\
\hline ERP system configuration & 2 \\
\hline ERP system tests & 2 \\
\hline Error management and troubleshooting & 1 \\
\hline Monitoring and performance measurement & 1 \\
\hline Knowledge management & 1 \\
\hline University (Company's) strategy / strategy fit & 1 \\
\hline Project champion & 1 \\
\hline Vendor tools and implementation methods & 1 \\
\hline
\end{tabular}

We will not describe each factor in detail in this paper. However, to provide a comprehensive understanding of the different CSFs and their concepts, we previously described most of the 30 factors (since most are also affecting ERP implementations in private enterprises) in [14].

The differences in the CSF frequencies are only minimal and are related to the small number of identified papers. Therefore, deriving CSFs and their differences in importance on HEIs ERP projects based on a literature review was just the first step in our research project. Thus, our follow up study ( $2^{\text {nd }}$ step) addresses this little amount of identified papers and their CSFs by investigating ERP projects at HEIs and the respective successes and/or problems.

\section{QUALITATIVE APPROACH - INTERVIEW STUDY}

\section{A. Study Design - Data Collection Methodology}

To gain a deeper understanding of the differences and importance of the CSFs for ERP system projects at HEIs, we used a qualitative exploratory approach within German universities and universities of applied sciences. As mentioned in the motivation we selected, to get initial insights, German HEIs due to our cultural background. The units of analysis in our study were the ERP implementation projects carried out within the HEIs' administrations. For the data collection, we conducted several interviews with members of the ERP implementation project teams or with the projects' responsible persons to identify the factors that they found to be relevant for the projects' success. In this process, we interviewed employees of nine HEIs located in Germany: one HEI with more than 40,000 students, three HEIs with 30,000 to 40,000 students, one HEI with 20,000 30,000 students, three HEIs with 10,000 to 20,000 students, and one HEI with less than 10,000 students.

Within these HEIs, due to the low number of ERP systems available for the specific requirements of universities, we have a low range of ERP systems (which cannot be named directly within this paper due to data protection). However, it can be stated that most of the HEIs have implemented a system from the same ERP manufacturer. Most of the implementation projects took place in the early or mid-2000s. The interviewees were indeed active in various areas of the administration, but they were also deeply integrated into the project and therefore could well provide information about the project. Five of those interviewees were ERP project managers, three were administrative IT managers, and one was a key user.

To gain a deep and detailed view of the HEIs and their 
structures as well as of the interviewees' experiences, we chose direct structured interviews as our method of data collection. The interviews were conducted in retrospect to the ERP projects in summer and autumn 2015. The interviews were designed as partially standardized interviews using open to semi-open questions as initial starting points for the conversation. An interview guideline was developed, based on the questions of [18], who conducted a similar study with an enterprise focus, as well as on the basis of our previous CSF studies, which had also an enterprise focus [10], [19]. We changed the questions to align with our identified CSFs (see Table II) in order to ensure that all of the factors were discussed in the interviews. The interview guideline consisted of five topic sections with 61 main questions and further sub-questions:

- Section A: Background information on the interview partner and the university

- Section B: Project management in the context of the selection and implementation of the ERP system

- Section C: Procedure, tools and methods used for the ERP implementation

- Section D: System analysis, system selection, technical implementation

- Section E: Final assessment of the ERP implementation

These questions were formulated in an open way so that it would be possible to identify "new" CSFs that were not currently identified in the literature review. This questionnaire was sent to interviewees before the interviews took place, to allow them to prepare for their interviews.

Due to the large physical distance, telephone interviews were conducted by the authors. For a more thorough analysis of the results, we recorded all interviews (the interviews typically took between 60 and 240 minutes) and transcribed them afterwards (resulting in about 160 pages of written text). The calls were recorded by the app TapeACall (https://www.tapeacall.com/). To evaluate the CSFs, the transcribed interviews were analyzed with reference to each CSF question block. All in all, the evaluation and assessment of the interview results followed the approach of [20]. The coding itself was carried out using the MAXQDA software (http://www.maxqda.com/).

\section{B. Results of the Interview Study}

After the coding, we again matched the answers and statements of the interviewees to the respective factor. Then each CSF was ranked according to a four-tier scale (see legend of Table III). This rating was done regarding the respective statements of the interviewees (similar to our approach used in [10]). After setting up this ranking of CSFs, we discussed the factor rating with other researchers in this field to reduce the subjectivity of the rating. Finally, this procedure resulted in a ranking of $30 \mathrm{CSF}$ according to the interviewees' statements and answers (Table III).

Compared to the results of the literature review (Table II) four new factors could be identified during the interviews (marked yellow within Table III): Key users, Requirements specification, Use of a steering committee, and Call for tenders; whereby four factors found in the literature review were not mentioned by the interviewees: Clear goals and objectives, Involvement of end-users and stakeholders, Environment, and Project champion. However, most of these new and not-found factors were only on medium ranks in both lists. Only the factors Involvement of end-users and stakeholders as well as Clear goals and objectives were among the top ten factors of the literature review.

TABLE III.

CSF's ACCORDING THE FOUR-TIER-SCALE RATING

\begin{tabular}{|c|c|c|}
\hline Rank & Factor & $\begin{array}{c}\text { Factor } \\
\text { rating } \\
(4-\text {-tier-scale) }\end{array}$ \\
\hline 1 & Culture of the HEI & 25 \\
\hline 2 & User training & 24 \\
\hline 3 & Communication & 23 \\
\hline \multirow{2}{*}{4} & ERP system configuration & 22 \\
\hline & ERP system tests & 22 \\
\hline 6 & $\begin{array}{l}\text { Go-Live approach / vendor tools and } \\
\text { implementation methods }\end{array}$ & 21 \\
\hline \multirow{2}{*}{7} & External consultants & 20 \\
\hline & Organizational fit of the ERP system & 20 \\
\hline 9 & Monitoring and performance measurement & 19 \\
\hline 10 & Error management and troubleshooting & 18 \\
\hline \multirow{3}{*}{11} & Balanced project team (cross-functional) & 17 \\
\hline & Business process reengineering & 17 \\
\hline & Project management & 17 \\
\hline 14 & Key users & 16 \\
\hline \multirow{5}{*}{15} & Requirements specification & 15 \\
\hline & IT structure and legacy systems & 15 \\
\hline & Data accuracy (analysis and conversion) & 15 \\
\hline & Top management support and involvement & 15 \\
\hline & Vendor relationship and support & 15 \\
\hline \multirow{2}{*}{20} & Change management & 14 \\
\hline & Skills, knowledge and expertise & 14 \\
\hline 22 & $\begin{array}{l}\text { Project leadership / empowered decision } \\
\text { makers }\end{array}$ & 13 \\
\hline \multirow{2}{*}{23} & Use of a steering committee & 11 \\
\hline & ERP system acceptance/resistance & 11 \\
\hline 25 & Call for tenders & 9 \\
\hline 26 & Available resources (e.g. employees, budget) & 8 \\
\hline 27 & Knowledge management & 7 \\
\hline \multirow{3}{*}{28} & University (Company's) strategy / strategy fit & 4 \\
\hline & Organizational structure & 4 \\
\hline & Interdepartmental cooperation & 4 \\
\hline \multicolumn{3}{|c|}{$\begin{array}{l}3 \text { - the factor was intensively considered during the project and } \\
\text { influenced the project significantly } \\
2-\text { the factor was stated and did have observable effects on the project } \\
1 \text { - the factor was stated but did not have any observable effects on the } \\
\text { project / was not seen as an important factor } \\
0 \text { - the factor was not mentioned at all } \\
\text { maximum possible rating on basis of } 9 \text { interviews }=27\end{array}$} \\
\hline
\end{tabular}

\section{CONCLUSION AND LIMITATIONS}

The aim of our study was to address the research field of CSFs for ERP implementation projects, with a specific focus on ERP projects at HEIs. Another objective was to compare the identified factors with the CSFs of ERP implementations in private enterprises.

As a first step, we carried out a systematic literature review to identify CSFs affecting HEIs' ERP projects. Our review turned up very little variety of papers focusing on those specific CSFs. All in all, we identified only 15 relevant 
papers dealing with the CSFs of ERP system projects at HEIs. From these existing studies, we derived 30 different CSFs (see Table II). Compared to a similar literature review that we conducted focusing on CSFs at private enterprises' ERP projects [14] - here, we identified 320 articles with this explicit focus - those 15 papers with an HEI focus reveal that this can still be seen as a clear lack of research.

To this end, we set up an empirical interview study with a specific HEI focus. We found that nearly all factors found in the literature review were mentioned by at least one interviewee. However, four CSFs were not mentioned, and we could identify four additional CSFs that were not found within the existing literature. Here, contrary to the ranking resulting from the literature reviews, we identified factors with a more technological focus as also important for those ERP projects. The factors ERP system tests and ERP system configuration, as top 5 factors, refer to more technological aspects. Hence, factors with an organizational characteristic could also be identified as part of the top 5 factors in our study (User training, Culture of the HEI, Communication).

Regarding our research questions, our study could show that most factors that influence the success of ERP system implementation projects in large-scale enterprises also influence ERP projects at HEIs. However, we found that the importance of the factors differs remarkably and that HEIs and also the ERP manufacturers have to be aware of these differences in the factors' characteristics. They should also focus on the technological aspects of the ERP implementations rather than focusing mainly on the organizational factors, as they are more important for the large-scale private enterprises.

Overall, we conclude that the specificities of different types of organizations/institutions and domains make it worthwhile to identify and rank CSFs within these fields instead of simply relying on what is known from other studies. Thus, revisiting CSF research from time to time, especially with a specific focus, still reveals new findings in this mature research field.

A few limitations of our study must be mentioned as well. For our literature review, we are aware that we cannot be certain that we have identified all relevant papers published in journals and conferences since we limited our selection to five databases and five international conferences. Another limitation is the coding of the CSFs. We tried to reduce the subjectivity by formulating coding rules and by discussing the coding of the CSFs with several independent researchers. However, other researchers may code the CSFs in other ways. For the interview study, the interviews conducted and data evaluated represent only an investigation on sample ERP projects in German HEIs. These results are limited to the specifics of these organizations and the experience of the interviewees. In light of this, we will conduct further case studies and some larger surveys to broaden the results of this investigation.

\section{REFERENCES}

[1] D. Allen, T. Kern, and M. Havenhand, "ERP Critical Success Factors: an exploration of the contextual factors in public sector institutions," in Proc. of the 35th Hawaii Int. Conf. on System Sciences (HICSS 2002), pp. 3062-3071, 2002, doi: 10.1109/HICSS.2002.994295.

[2] N. Pollock and J. Cornford, "ERP systems and the university as a "unique" organisation," Inform. Techn. \& People, vol. 17, no. 1, pp. 31-52, 2004, doi: 10.1108/09593840410522161.

[3] R. Alt and G. Auth, "Campus-Management-System," Wirtschaftsinformatik, vol. 52, no. 3, pp. 185-188, 2010, doi: 10.1007/s11576-010-0224-4.

[4] A.A. Rabaa'i, W. Bandara, and G. Gable, "ERP systems in the higher education sector: a descriptive study," in Proc. of the 20th Australasian Conf. on Inform. Syst. (ACIS 2009), pp. 456-470, 2009.

[5] L. Lechtchinskaia, J. Uffen, and M.H. Breitner, "Critical Success Factors for Adoption of Integrated Information Systems in Higher Education Institutions: A Meta-Analysis," in Proc. of the 17th Americas Conf. on Inform. Syst. (AMCIS 2011), 2011.

[6] C. Leyh and C. Hennig, "ERP- and Campus Management Systems in German Higher-Education Institutes," in CONFENIS-2013 - 7th Int. Conf. on Research and Practical Issues of Enterprise Inform. Syst. (Schriftenreihe Informatik, Vol. 41), B. Josef, J. Pavel, N. Ota, and T.A. Min, Eds., Linz, Austria: Trauner Publishing, pp. 29-44, 2013.

[7] H. Schilbach, K. Schönbrunn, and S. Strahringer, "Off-the-shelf applications in higher education: a survey on systems deployed in Germany," in Proc. of the Inter. Conf. on Business Inf. Syst. 2009 (BIS 2009), pp. 242-253, 2009, doi: 10.1007/978-3-642-03424-4 30.

[8] H. Klug, "Erfolgsfaktoren bei der Umstellung von Informationssystemen an Hochschulen," in Proc. of the 9th Wirtschaftsinformatik Conf. (WI 2009), 2009.

[9] A. Jones, J. Robinson, B. O'Toole, and D. Webb, "Implementing a bespoke supply chain management system to deliver tangible benefits," The Int. Journ. of Advanced Manufacturing Techn., vol. 30, no. 9-10, pp. 927-937, 2006, doi: 10.1007/s00170-005-0065-2.

[10] C. Leyh, "Which Factors Influence ERP Implementation Projects in Small and Medium-Sized Enterprises?," in Proc. of the 20th Americas Conf. on Inform. Syst. (AMCIS 2014), 2014.

[11] T.M. Somers and K. Nelson, "The impact of critical success factors across the stages of enterprise resource planning implementations," in Proc. of the 34th Hawaii Int. Conf. on System Sciences (HICSS 2001), 2001, doi: 10.1109/HICSS.2001.927129.

[12] S. Saad, T. Perera, P. Achanga, E. Shehab, R. Roy, and G. Nelder, "Critical success factors for lean implementation within SMEs," Journ. of Manufacturing Techn. Manag., vol. 17, no. 4, pp. 460-471, 2006.

[13] S. Finney and M. Corbett, "ERP implementation: a compilation and analysis of critical success factors," Business Process Manag. Journ., vol. 13, no. 3, pp. 329-347, 2007, doi: 10.1108/14637150710752272.

[14] C. Leyh and P. Sander, "Critical Success Factors for ERP System Implementation Projects: An Update of Literature Reviews," in Enterprise Systems: Strategic, Organizational and Technological Dimensions (LNBIP, Vol. 198), D. Sedera, N. Gronau and M. Sumner Eds., New York, USA: Springer, pp. 45-67, 2015, doi: 10.1007/978-3319-17587-4_3.

[15] J. Webster and R.T. Watson, "Analyzing the past to prepare for the future: Writing a literature review," MIS Quarterly, vol. 26, no. 2, pp. 13-23, 2002.

[16] J. Jesson, L. Matheson, and F.M. Lacey, Doing your literature review: Traditional and systematic techniques, London: Sage Publ., 2011.

[17] C. Leyh, "Critical Success Factors for ERP System Implementation Projects: A Literature Review," in Advances in Enterprise Information Systems II, C. Møller and S. Chaudhry, Eds., Leiden, The Netherlands: CRC Press/Balkema, pp. 45-56, 2012.

[18] F.F.H. Nah and S. Delgado, "Critical success factors for enterprise resource planning implementation and upgrade," Journ. of Computer Inf. Syst., vol. 46, no. 5, pp. 99-113, 2006.

[19] C. Leyh and P. Muschick, "Critical Success Factors for ERP system Upgrades - The Case of a German large-scale Enterprise," in: Proc. of the 19th Americas Conf. on Inf. Syst. (AMCIS 2013), 2013.

[20] U. Flick, Qualitative Forschung: Theorie, Methoden, Anwendung in Psychologie und Sozialwissenschaften, Reinbek near Hamburg, Germany: Rowohlt Taschenbuch Verlag, 1995. 